\title{
Differential responses to line orientation after training to a blank stimulus
}

\author{
ANDREW KARR* \\ Columbia University, New York, N.Y. 10027
}

Pigeons were trained to respond with variable-interval food reinforcement in the presence of a green key. During extinction, lines of different orientation were projected on the green field. Responding to these stimuli was differential but idiosyncratic. These findings may present methodological problems to Es using two dimensions to measure gradients of generalization of inhibition.

Jenkins \& Harrison (1962), Honig, Boneau, Burnstein, \& Pennypacker (1963), and Jenkins (1965) have described a method for obtaining generalization gradients of inhibition which is analogous to conventional methods for obtaining gradients of excitation. This method employs an S- which is orthogonal to the dimension of the generalization test. For example, Honig et al (1963) obtained inhibitory gradients on a line-tilt continuum after training pigeons on a successive discrimination between $S+$ (blank white key) and $S-$ (white key bisected by a black vertical line). Since the blank (no line) stimulus is presumably equidistant from all stimuli on the line-tilt continuum, generalized response strength from the blank stimulus can be assumed to be equal to all line stimuli (Farthing \& Hearst, 1968, p. 743).

The experiment reported here was designed to test the assumption that uniform responding to line orientation occurs after training to a blank stimulus.

\section{SUBJECTS}

Three male White Carneaux pigeons were maintained at $80 \%$ of their free-feeding weights. They were experimentally naive with respect to line orientation, although they had previously served in a variety of hue discrimination experiments.

\section{APPARATUS}

The experiment was conducted in a Lehigh Valley single-key pigeon chamber with houselight, grain magazine, and white noise source. The key was transilluminated by a standard in-line-display unit capable of producing a green field on which white lines of different orientation could be superimposed. The experiment was programmed by standard relay equipment in a separate room. Data

* Requests for reprints should be addressed to Andrew Karr, Department of Psychology, Columbia University, New York, N.Y. 10027, I would like to thank Jay McClelland for running part of this experiment, and also J. A. Nevin for his help in the preparation of this paper and his general good spirits. were recorded on counters and a cumulative recorder.

\section{PROCEDURE}

The Ss were trained to respond to the green key. The key was lighted for 1-min periods, during which reinforcements became available on a VI 3-min schedule. The key was then darkened for $5 \mathrm{sec}$ (time-out), and then the cycle began again. Each session was composed of 60 cycles of $\mathrm{S}+$ and time-out. When all three birds responded consistently throughout several successive sessions (determined by visual inspection of cumulative records), testing began with the line stimuli.

The test sessions began as the training sessions had, but, after five cycles of VI 3-min/time-out, reinforcements were no longer available. During the next 54 cycles, nine white lines, oriented as shown in the top panel of Fig. 1, were superimposed with equal frequency in blocks of nine on the green field. Each of these nine compound stimuli was presented for six 1-min periods. This series of 54 stimuli was then repeated two more times until responding had virtually ceased.

This procedure is similar to the preference tests used by Rosen (1970) and Selekman (1970) to measure responding to stimuli differing in wavelength after training to white fields.

\section{RESULTS AND DISCUSSION}

The three bottom panels of Fig. 1 show relative response gradients for each $\mathrm{S}$ for the extinction test. These gradients are cumulative for all three tests and are representative of individual test data. All birds responded differentially to line orientation, although the peaks of the gradients vary across birds. This indicates that they were probably not responding differentially to brightness, due to different bulb outputs.

This experiment shows that uniform responding to line orientation does not occur after training to a blank stimulus. This does not mean that the continua are not orthogonal. It is doubtful that training with blank stimuli biases organisms toward line orientation. It is more likely that such training raises response strength enough for preexperimental preferences to be exhibited in extinction. To prove this, one would have to raise $S s$ in an environment in which no preferences could form (e.g., Peterson, 1962) and then show that generalized response strength from the blank stimulus was not differential.
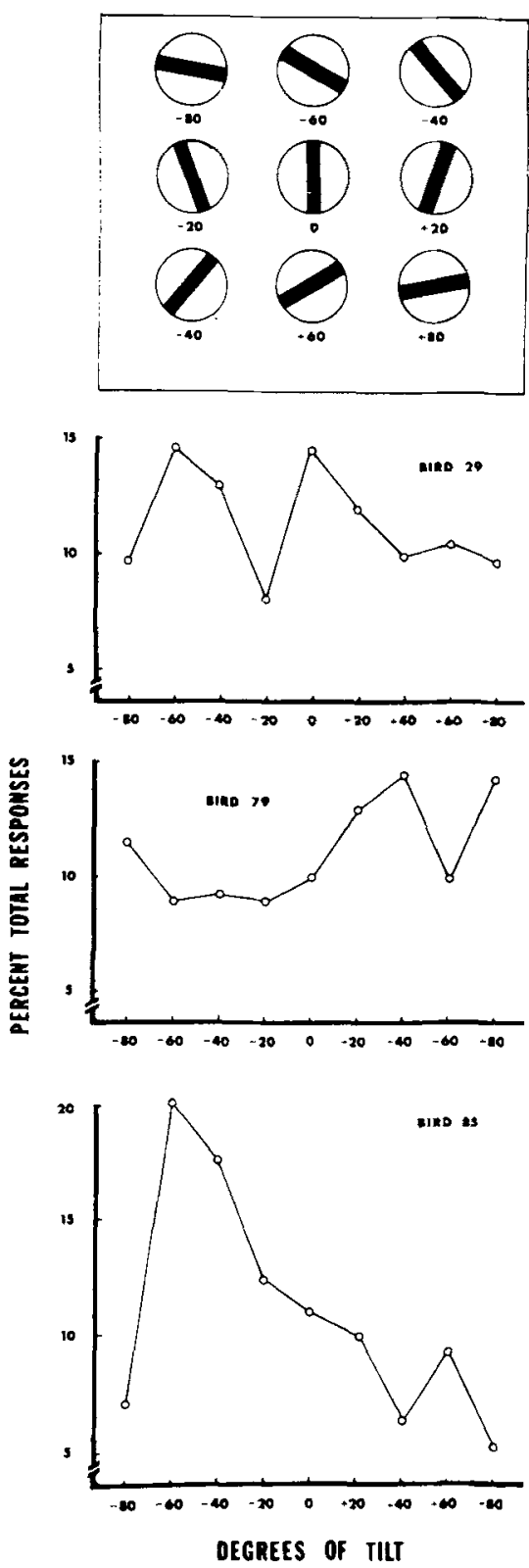

Fig. 1. The top panel illustrates the nine orientations of line stimuli used in this experiment. The lower panels show the percent of the total responses, cumulative for three tests, to each orientation. The gradients are based on over 2,000 responses by each bird. 
REFERENCES

FARTHING, G. W., \& HEARS $\dot{T}$, E. Generalization gradients of inhibition after different amounts of training. Joumal of the Experimental Analysis of Behavior, 1968, 11, 743-752.

HONIG, W. K., BONEAU, C. A. BURNSTEIN, K. R., \& PENNYPACKER, H. S. Positive and negative generalization gradients obtained after equivalent training conditions. Journal of Comparative \& Physiological Psychalogy, 1963, 56, 111-116.

JENKINS, H. M. Generalization gradients and the concept of inhibition. In $D$ Mostofsky (Ed.), Stimulus generalization. Palo Alto: Stanford University Press 1965. Pp. 55-61.

JENKINS, H. M.. \& HARRISON, R. H.
Generalization gradients of inhibition following auditory discrimination learning. Journal of the Experimental Analysis of Behavior, 1962, 5, 435-441.

PETERSON, N. Effect of monochromatic rearing on the control of responding by wavelength. Science, $1962,136,774-775$.

ROSEN, A. Determinants of inhibition: The effect of massed extinction, behavioral contrast, and reinforcement. Unpublished doctoral dissertation, Columbia University, 1970 .

SELEKMAN, W. Preference gradients and post discrimination gradients along the wavelength continuum after training to white light. Unpublished doctora dissertation, Columbia University, 1970.

\title{
A sex difference in the extinction of avoidance behavior in rats
}

\author{
WILLIAM W. BEATTY and PATRICIA ANN BEATTY \\ North Dakota State University, Fargo, N. Dak. 58102 \\ and \\ ROBERT E. BOWMAN \\ University of Wisconsin, Madison, Wis. 53706
}

Significantly more females than males met criterion for the acquisition of a shuttle-avoidance response. Among $S$ s meeting criterion, females displayed increased resistance to extinction of the avoidance response. The relationship between sex differences in avoidance behavior and adrenocortical functioning was discussed.

Recently, Beatty \& Beatty (1970) demonstrated that female rats acquire a two-way active avoidance response more rapidly than males over a wide range of US intensities. Manipulations which increase circulating levels of ACTH also enhance the acquisition of avoidance behavior by males at high US intensities (Beatty, Beatty, Bowman, \& Gilchrist, 1970), and ACTH is known to play an important role in the maintenance of avoidance responding during extinction tests (de Wied, 1966; Murphy \& Miller, 1955). Female rats have larger anterior pituitary and adrenal glands (Swanson \& van der Werff ten Bosch, 1963) and higher blood corticosterone levels

(Ader, 1968; Kitay, 1961), suggesting that their ACTH levels are also higher. If this hypothesis is correct, then females would be expected to be more resistant to the extinction of an active avoidance response. The present experiment tested this hypothesis and examined the relationship of acquisition and extinction performance to resting plasma corticosterone levels in both sexes. SUBJECTS

Thirty-six rats of the Holtzman strain, 18 of each sex, served as Ss. Males weighed $420-560 \mathrm{~g}$; females weighed $310-440 \mathrm{~g}$. All Ss had prior breeding experience. Other work (Beatty \& Beatty, 1970) indicates that, in adult rats of this strain, age, weight, and reproductive experience do not affect avoidance acquisition. The Ss were caged singly in a room with continuous illumination and were fed Wayne Lab Blox and water ad lib. One female $\mathbf{S}$ was pregnant and was dropped from the experiment.

\section{PROCEDURE}

Acquisition and extinction tests were conducted in two identical shuttleboxes that have been described elsewhere (Schwartzbaum, Green, Beatty, \& Thompson, 1967). Each acquisition or extinction session consisted of a 5-min period, during which $S$ could shuttle freely from one side of the lighted shuttlebox to the other, followed by 25 test trials presented on a 60-sec FI schedule. During acquisition, the CS (offset of light in the compartment occupied by S) preceded the onset of the US by $10 \mathrm{sec}$ and was terminated by a shuttling avoidance response. Otherwise, the CS overlapped the US, and both were terminated by an escape response. No adaptation tests were run because previous work (Beatty \& Beatty, 1970) indicated that rats of this strain do not escape the offset of light under the present conditions. US intensity was $1.0 \mathrm{~mA}$.

Acquisition began on the first experimental session and continued until $S$ met a criterion of at least 20 avoidance responses out of 25 trials for two consecutive sessions or until $S$ received 200 training trials. Extinction tests began the day after $S$ met the acquisition criterion and continued for three consecutive sessions (75 trials). During extinction, the CS remained on for $10 \mathrm{sec}$ unless terminated by a shuttling response. If $S$ failed to shuttle during the 10 -sec CS period, the CS terminated automatically and the ITI began. Other parameters were the same as in acquisition.

Several days after the end of extinction tests, all Ss were sacrificed under ether anesthesia. Blood was withdrawn from the right ventricle, centrifuged, and the plasma frozen for corticosterone assay by the protein-binding method (Murphy, 1967). Data on this measure were lost for one female that met acquisition criterion.

\section{RESÚLTS}

Performance during acquisition is shown in Table 1. Fewer than $30 \%$ of males, but greater than $80 \%$ of females, met the acquisition criterion $\left(x^{2}=8.41, \quad \mathrm{df}=1, \quad \mathrm{p}<.01\right)$. Nevertheless, the performance of male and female $S$ s that did meet criterion was quite similar. There were no significant differences between these groups in the number of escape or avoidance responses to criterion or in the number of avoidance responses 